\title{
Synergetic Treatment of Ascorbic Acid and Nicotine Ameliorates Aluminium Induced Neurotoxicity in the Prefrontal Cortex of Wistar Rat
}

\author{
Taiwo A. Abayomi ${ }^{1 *}$, Olorunfemi S. Tokunbo ${ }^{1}$, Temilola D. Olawore ${ }^{1}$, Olawale A. Abayo- \\ mi $^{2}$, Ajilore S. Bamidele ${ }^{3}$, Abiodun Akinyemi ${ }^{1}$ \\ ${ }^{1}$ Department of Anatomy, Faculty of Basic Medical Sciences, College of Health Sciences, Osun State \\ University, PMB 4494, Osogbo, Osun State, Nigeria. \\ ${ }^{2}$ Department of Radiology, Faculty of Clinical Sciences, Ekiti State University, Ekiti State, Nigeria \\ ${ }^{3}$ Department of Biochemistry, Faculty of Basic Medical Sciences, College of Health Sciences, Osun \\ State University, PMB 4494, Osogbo, Osun State, Nigeria
}

\begin{abstract}
*Correspondence should be addressed to Taiwo A. Abayomi: taiwo.abayomi@uniosun.edu.ng
Received 27th June 2021; Revised 16th June 2021; Accepted 30 July 2021

(C) 2021 Abayomi et al. Licensee Pan African Journal of Life Sciences an official publication of Faculty of Basic Medical Sciences, Ladoke Akintola University of Technology, Ogbomoso. This is an Open Access article distributed under the terms of the Creative commons Attribution License (https://creativecommons.org/licenses/BY/4.0), which permits unrestricted use, distribution, and reproduction in any medium, provided the original work is properly cited.
\end{abstract}

\begin{abstract}
Background: Though the neuroprotective roles of ascorbic acid are well established, the therapeutic role of nicotine in various neurological disorders is attracting increasing attention. This study evaluated the putative ameliorative role of the synergetic treatment of nicotine and ascorbic acid against neurodegenerative consequences associated with free radical species and amyloid plaques generation in adult male Wistar rats
\end{abstract}

Methods: A total of 35 Wistar rats were distributed into five groups labeled A-E. Group A served as the control group; animals in group B were treated with $100 \mathrm{mg} / \mathrm{kg}$ body weight of aluminium chloride $\left(\mathrm{AlCl}_{3}\right)$ for 21 days. Group C animals were treated with $100 \mathrm{mg} / \mathrm{kg}$ body weight of aluminium chloride for 21 days and post-treated with $14 \mathrm{mg} / \mathrm{kg}$ body weight of nicotine for 21 days. Group D was treated with $100 \mathrm{mg} / \mathrm{kg}$ body weight of aluminium chloride for 21 days and post-treated with $100 \mathrm{mg} / \mathrm{kg}$ bodyweight of ascorbic acid for 21 days. Group E animals were treated with $100 \mathrm{mg} / \mathrm{kg}$ body weight of aluminium chloride for 21 days and post-treated with $100 \mathrm{mg} / \mathrm{kg}$ bodyweight of ascorbic acid and $14 \mathrm{mg} / \mathrm{kg}$ body weight of nicotine. On completion of treatments, the prefrontal cortex was excised and processed for biochemical and histochemical examinations.

Results: Oxidative stress was evident from the diminished level of catalase and glutathione peroxidase and elevated lipid peroxidation levels in animals administered with aluminium in addition to the presence of amyloid plaques in these animals. However, synergetic administration of ascorbic acid and nicotine attenuated these oxidative and histochemical perturbations induced by aluminium.

Conclusion: Synergetic treatment with ascorbic acid and nicotine provided better ameliorative potential against aluminium-induced neurotoxicity compared to either ascorbic acid or nicotine treatments alone

Keywords: Neurotoxicity, Ascorbic acid, nicotine, amyloid plaques, oxidative stress 


\subsection{INTRODUCTION}

Oxidative stress refers to a disturbance in the prooxidantantioxidant balance in favor of the former, leading to potential damage [1]. This imbalance results from either a decrease in antioxidant levels or an increase in reactive oxygen species (ROS), or reactive nitrogen species (RNS). Oxidative stress plays a crucial role in inducing damage to neuronal proteins, lipids, and organelles in the brains of subjects with neurodegenerative diseases [2]. Also, oxidative stress has been linked to abnormal aggregation and/or mutation of proteins such as betaamyloid, parkin, and $\alpha$-synuclein [3-4]. In addition to protein mutations, environmental factors such as pesticides, ethanol consumption, metals, and the accumulation of somatic mitochondrial DNA mutations have negatively affected brain homeostasis, leading to neurodegeneration [5-6]. Protein aggregation may disrupt the mitochondrial membrane potential, impair respiratory enzyme activities and result in reduced ATP generation, energy deficits, and increased levels of reactive oxygen species $\left(\mathrm{O}_{2}-\right.$ and $\left.\mathrm{H}_{2} \mathrm{O}_{2}\right)$. In turn, oxidative stress can also affect protein degradation by deteriorating the ubiquitinproteasome system [7-8]. Furthermore, the release of cytochrome $\mathrm{C}$ from damaged mitochondria can trigger the activation of apoptotic cascades and neuronal cell death [9].

Aluminum (Al) has been reported to induce excessive ROS production in the brain. The main routes of aluminium consumption by humans are inhalation, ingestion, and dermal contact, while major sources of exposure are drinking water, food, beverages, and aluminium containing drugs [10]. Aluminium $\left(\mathrm{AlCl}_{3}\right)$ is a widely recognized neurotoxin that inhibits several biologically essential functions, inducing severe behavioral abnormalities, impaired cognitive functions, and metabolic dysfunction [11].

Nicotine, a major alkaloid present in tobacco products and in smaller amounts in potatoes, tomatoes, and eggplants, acts as an agonist on neurons and other cells throughout the body that express nicotinic acetylcholine receptors (nAChRs) [12]. Nicotine readily crosses the blood-brain barrier, mimics the endogenous neurotransmitter acetylcholine, and may interact with more than one receptor subtype. Any given nicotinic receptor is comprised of five subunits forming an ionophoric channel [13]. Nicotine may also affect more than one of the receptor subtypes and act on more than one binding site in the brain. Nicotinic receptors are involved in the developing and ongoing maintenance of the mammalian nervous system and are widely distributed in the human brain. Though nicotine has been reported to be therapeutic in certain neurodegenerative diseases providing neuroprotection in the central nervous system [14], however, some studies have shown that nicotine administration is associated with oxidative damage in the periphery and central nervous system by inducing the generation of reactive oxygen species [13]. Evidence suggests that nicotine may have antioxidant properties in the central nervous system [15]. The possibility that nicotine might be used to treat some symptoms of certain neurodegenerative diseases underlies the necessity to keep its prooxidant property in check.

Ascorbic acid also known as Vitamin $\mathrm{C}$, is a chainbreaking antioxidant that halts the propagation of peroxidative processes [16]. It plays a role in many enzyme reactions, including those leading to the synthesis of amino acids and peptide hormones. Ascorbic acid behaves as a ROS scavenger and may effectively combat oxidative damage under conditions of increasing oxygen concentrations and apoptosis [17]. Being a six-carbon lactone and an antioxidant, it is an excellent donor of electrons, preventing other compounds from being oxidized. This study, therefore, evaluated the synergistic neurotherapeutic effects of ascorbic acid and nicotine complex against $\mathrm{AlCl}_{3}$ induced neurotoxicity with particular emphasis on the prefrontal cortex.

\subsection{METHODOLOGY}

\subsection{Animal Procurement and Handling}

A total of thirty-five (35) adult Wistar rats weighing between 150 to $160 \mathrm{~g}$ were procured and housed in the Animal Holding Facility of Osun State University, Osogbo. The animals were maintained in a controlled environment $(22 \pm 2 \mathrm{C} ; 14 \mathrm{~h}$ of light from $06: 00 \mathrm{~h}$ to 20:00 h) with free access to pelletized rat chow, and water was given ad libitum. They were acclimatized for two weeks before the experiment. Animals were treated humanely and with regard to the alleviation of suffering for the care and use of laboratory animals. Animal handling procedure for the care and use of laboratory animals was adhered to according to the National Institutes of Health Handbook (NIH Guidelines 
No.2.4.3.8023, updated 1978). Ethical approval was granted by the University of Ilorin Ethics Review Committee, Nigeria (UERC/ASN/2019/1463).

\subsection{Chemicals}

Ascorbic Acid (Cat. No.: 1043003) and aluminium chloride $\left(\mathrm{AlCl}_{3}\right)$ salt (Cat. No.: 563919) were obtained from Sigma - Aldrich (USA). 95\% Nicotine (Cat. No.: 412634) was purchased from British Drug House (BDH) Chemical Ltd, London. Distilled water obtained from the Department of Biochemistry, Osun State University was used to dissolve these chemicals.

\subsection{Animal Treatment Groups}

The rats were randomly distributed into five groups ( $\mathrm{n}=$ 7 per group).

Group A (control) - received distilled water for 21 days

Group B $\left(\mathrm{AlCl}_{3}\right)$ - received $100 \mathrm{mg} / \mathrm{kg}$ body weight of $\mathrm{AlCl}_{3}$ for 21 days

Group $\mathrm{C}\left(\mathrm{AlCl}_{3}+\right.$ nicotine $)$ - received $100 \mathrm{mg} / \mathrm{kg}$ body weight of $\mathrm{AlCl}_{3}$ for the first 21 days after which $14 \mathrm{mg} / \mathrm{kg}$ body weight of nicotine was administered for the next 21days.

Group D $\left(\mathrm{AlCl}_{3}+\right.$ Ascorbic acid) - received $100 \mathrm{mg} / \mathrm{kg}$ bodyweight of $\mathrm{AlCl}_{3}$ for the first 21days after which $100 \mathrm{mg} / \mathrm{kg}$ body weight of ascorbic acid was administered for the next 21 days

Group E $\left(\mathrm{AlCl}_{3}+\right.$ Ascorbic acid + nicotine $)$ - received $100 \mathrm{mg} / \mathrm{kg}$ body weight of $\mathrm{AlCl} 3$ for the first 21 days, followed by the co-administration of $100 \mathrm{mg} / \mathrm{kg}$ body weight of ascorbic acid and $14 \mathrm{mg} / \mathrm{kg}$ body weight of nicotine for next 21 days.

Nicotine was intraperitoneally administered with an insulin syringe, while $\mathrm{AlCl}_{3}$ and Ascorbic acid were administered orally via oral cannula

\subsection{Animal Sacrifice, Tissue Collection, and Processing}

Animals for histochemical analyses were euthanized by $20 \mathrm{mg} / \mathrm{kg}$ of ketamine intraperitoneal administration, followed by transcardial perfusion in the left ventricle with normal saline to remove blot clots and 4\% paraformaldehyde (PFA). The skull was opened, brain dissected, and rinsed in $0.25 \mathrm{M}$ sucrose three times each and then post-fixed in 4\% PFA for 24 hours. PFA brain tissues were dehydrated with ascending grades of alcohol, cleared in xylene, infiltrated, and embedded in molten paraffin wax to form tissue blocks [18]. The paraffin tissue blocks were cut into serial coronal sections of $5 \mu$ using a Thermo Scientific HM 325 rotatory microtome.

\subsection{Histochemical Study}

Serial coronal sections of the prefrontal cortex were transferred to albuminised slides and placed on a hot plate to dry. The slides were dewaxed in two changes of xylene, rehydrated through descending grades of alcohol $(100 \%, 95 \%, 90 \%, 70 \%$, and $50 \%)$ and water. Deparaffinized slides for Congo red staining were stained according to the method of Puchtler et al., [19] in congo red working solution for 10 minutes, rinsed in distilled water, differentiated in alkaline alcohol solution, rinsed, counterstained in Gill's haematoxylin, rinsed, blued in ammonia water, rinsed, dehydrated, cleared in xylene and mounted in synthetic resin. Histochemical analysis of the prefrontal cortex was captured using Olympus binocular research microscope (Olympus, New Jersey, USA) which was connected to a 5.0 MP Amscope Camera (Amscope Inc, USA).

\subsection{Biochemical Analysis}

Brain tissues for biochemical studies were excised from the animals' skull following cervical dislocation of the animals to prevent biochemical redox interference with an anaesthetic agent. The excised brain tissues were rinsed in $0.25 \mathrm{M}$ sucrose, and the prefrontal cortex tissue was isolated and homogenized immediately using an automatic homogenizer. The prefrontal cortex tissue homogenate was centrifuged at 2000rpm for 10 mins at $4 \mathrm{oC}$ and the supernatant aspirated into $5 \mathrm{ml}$ plain serum bottles for quantification of the oxidative enzyme activities. Catalase (CAT), Lipid peroxidation (MDA), and Glutathione Peroxidase (GPx), were measured spectrophotometric to quantify the activities of these enzymes using specific assay kits in accordance to the manufacturer's instructions indicated in the assay kits.

\subsection{Data Analysis}

Results obtained from quantitative studies were analysed using GraphPad Prism Version 8.0.1 for Windows (Graph Pad Software Inc., San Diego, CA, United States) and tested for variance analysis (ANOVA) with Tukey's multiple comparisons test. Significance was set at $\mathrm{p}<0.05$. 


\subsection{RESULTS}

\subsection{Ascorbic Acid and Nicotine Complex Up-regulates Catalase Level}

The enzymatic activity of catalase in the prefrontal cortex was measured in this study. Aluminium treatment decreased the level of catalase as observed in the $\mathrm{AlCl} 3$ treated group (group B). The decreased level of catalase in this group of animals was significant when compared with the control (group A) animals $(\mathrm{P}<0.05)$. The enzymatic concentration of catalase in animals posttreated with nicotine (Group C) showed a statistically significant $(\mathrm{P}<0.05)$ increase in catalase concentration in comparison to animals administered with $\mathrm{AlCl}_{3}$ only. Also, animals post-treated with ascorbic acid and nicotine complex (group E) showed a significant $(\mathrm{P}<0.05)$ increase in catalase levels when compared with animals post-treated with only nicotine (group C). (Figure 1)

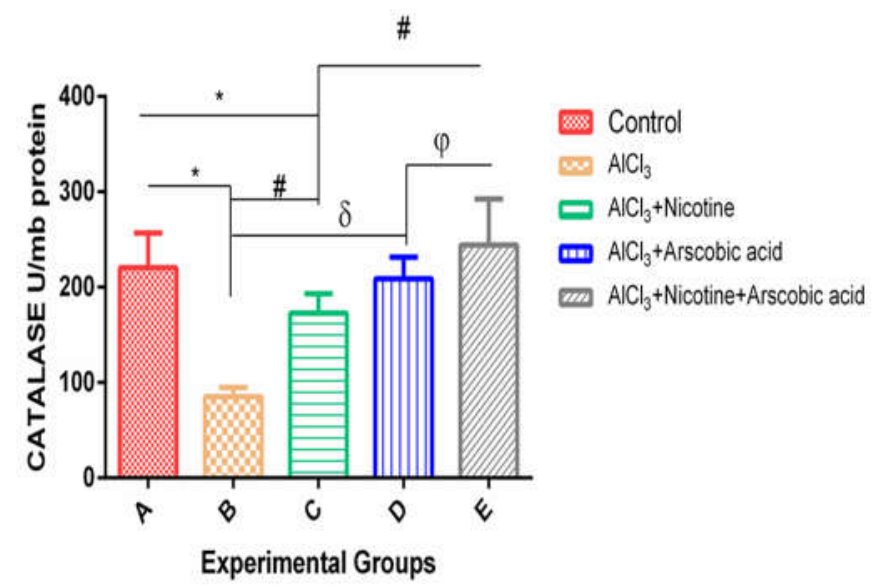

Figure 1: Activities of Catalase in the Prefrontal Cortex of Experimental Animals.

$\mathrm{A}=$ control, $\mathrm{B}=$ Ascorbic $\mathrm{A}=$ control, $\mathrm{B}=\mathrm{AlCl}_{3}, \mathrm{C}=\mathrm{AlCl}_{3}+$ Nicotine, $\mathrm{D}=$ $\mathrm{AlCl}_{3}+$ Ascorbic acid, $\mathrm{E}=\mathrm{AlCl}_{3}+\mathrm{Nicotine}+$ Ascorbic acid. *The significant level of difference in comparison to the control group (Group A). \#The significant level of difference in comparison to group C. $\boldsymbol{\delta}$ The significant level of difference in comparison to group D. $\varphi$ The significant level of difference in comparison to group E.

\subsection{Ascorbic Acid and Nicotine Complex Reduces Lipid Peroxidation}

Malondialdehyde expression is a marker of lipid peroxidation. In this study, animals administered with $\mathrm{AlCl}_{3}$ only (group B) were observed to express significantly $\quad(\mathrm{P}<0.05) \quad$ increased levels of malondialdehyde when compared with the control animals (group A) and animals post-treated with nicotine and ascorbic acid complex (group E). The level of malondialdehyde expressed in animals post-treated with nicotine only (group C) also increased significantly compared to those post-treated with ascorbic acid only (group D). Also, a significant decrease in malondialdehyde levels was observed in animals posttreated with ascorbic acid only (group D) when compared to those treated with $\mathrm{AlCl}_{3}$ only (group B) and posttreated with nicotine only (group C) (Figure 2).

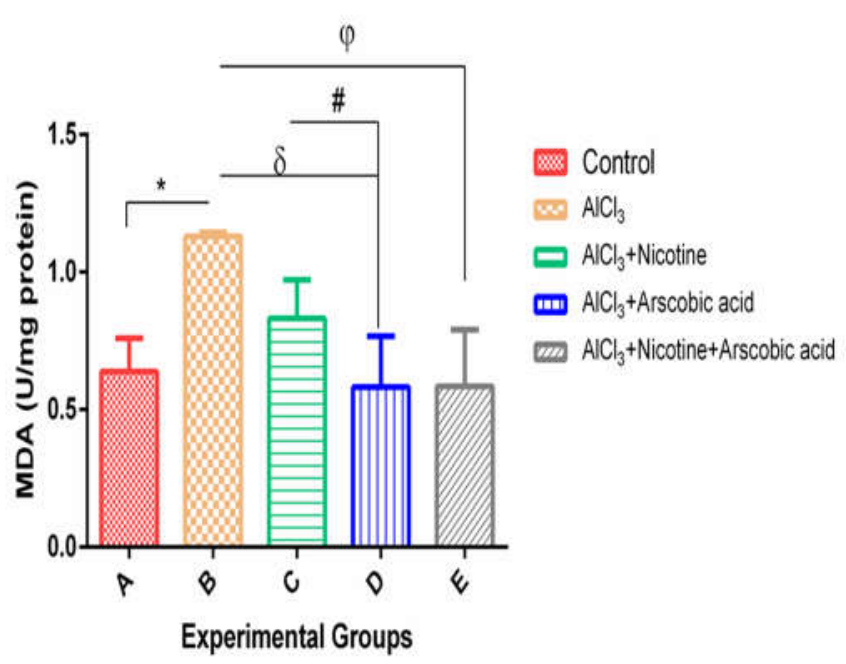

Figure 2: Activities of Malondialdehyde in the Prefrontal Cortex of Experimental Animals.

$\mathrm{A}=$ control, $\mathrm{B}=$ Ascorbic $\mathrm{A}=$ control, $\mathrm{B}=\mathrm{AlCl}_{3}, \mathrm{C}=\mathrm{AlCl}_{3}+$ Nicotine, $\mathrm{D}=$ $\mathrm{AlCl}_{3}+$ Ascorbic acid, $\mathrm{E}=\mathrm{AlCl}_{3}+\mathrm{Nicotine}+$ Ascorbic acid. *The significant level of difference in comparison to the control group (Group A); \#The significant level of difference in comparison to group $\mathrm{C} ; \boldsymbol{\delta}$ The significant level of difference in comparison to group D; $\varphi$ The significant level of difference in comparison to group $\mathrm{E}$.

3.3 The Synergetic Treatment of Nicotine and Ascorbic Acid Boosted the Prefrontal Cortex Glutathione Peroxidase Profile

Rats administered with $\mathrm{AlCl}_{3}$ only (group $\mathrm{B}$ ) had significantly $(\mathrm{P}<0.05)$ reduced levels of GPx when compared to the control group and animals post-treated with nicotine (group C), ascorbic acid (group D), as well as those post-treated with nicotine and ascorbic acid complex (group E). The enzymatic concentration of glutathione peroxidase in animals post-treated with nicotine and ascorbic acid (Group E) showed no significant difference in comparison to the control group (group A). (Figure 3)

\subsection{Histochemical Demonstration of Amyloid Plaques}

Amyloid plaque demonstration was carried out in this study using Congo red histochemical staining technique. Accumulated amyloid plaques in the prefrontal cortex 


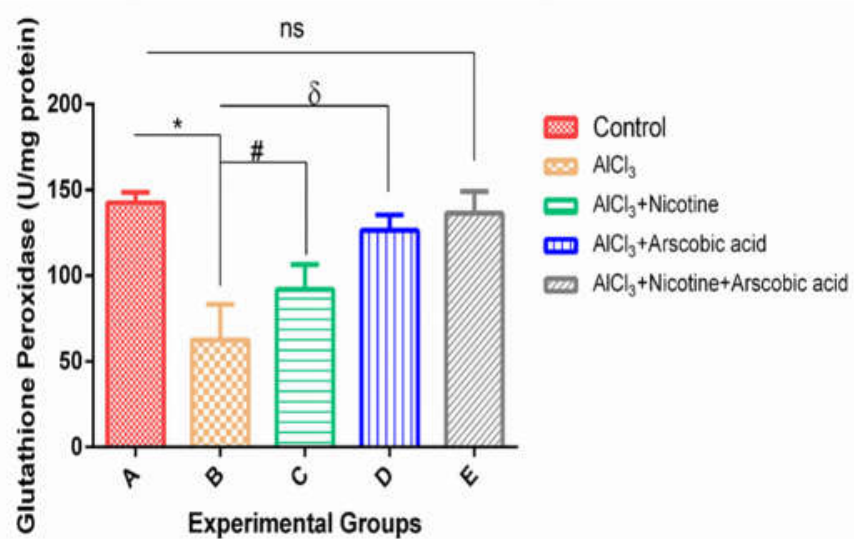

Figure 3: Activities of Glutathione Peroxidase in the Prefrontal Cortex of Experimental Animals.

$\mathrm{A}=$ control, $\mathrm{B}=$ Ascorbic $\mathrm{A}=$ control, $\mathrm{B}=\mathrm{AlCl}_{3}, \mathrm{C}=\mathrm{AlCl}_{3}+$ Nicotine, $\mathrm{D}=$ $\mathrm{AlCl}_{3}+$ Ascorbic acid, $\mathrm{E}=\mathrm{AlCl}_{3}+$ Nicotine + Ascorbic acid. $*$ The significant level of difference in comparison to the control group (Group A); \# The significant level of difference in comparison to group $\mathrm{C} ; \boldsymbol{\delta}$ The significant level of difference in comparison to group $\mathrm{D} ; \varphi$ The significant level of difference in comparison to group $\mathrm{E}$.

(red dotted circle) were observed in rats administered with $\mathrm{AlCl}_{3}$ only (group B). There were traces of amyloid plaques in animals post-treated with ascorbic acid (group D) though this accumulation was mild compared to group $\mathrm{B}$ animals. The absence of amyloid plaques was observed in control (group A), $\mathrm{AlCl3}+$ nicotine (C), and $\mathrm{AlCl}_{3}{ }^{+}$Nicotine + Ascorbic acid (E) animals. (Figure 4)

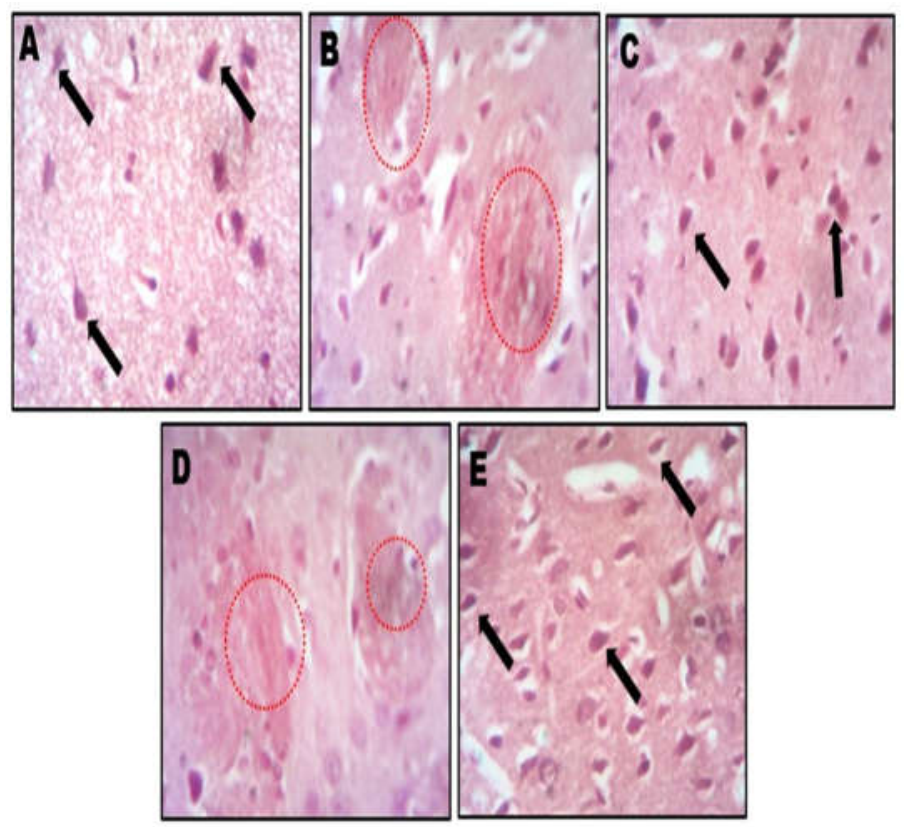

Figure 4: Representative Photomicrographs of the Congo Red Stain Showing Amyloid Plaques in the Prefrontal Cortex of the Experimental Animals (magnification x400).

Plaques were present in all the photomicrographs of animals in groups B and $\mathrm{D}$, while plaques were absent in all the photomicrographs of animals in groups $\mathrm{C}$ and $\mathrm{E}\left(\mathrm{A}=\right.$ control, $\mathrm{B}=\mathrm{AlCl}_{3}, \mathrm{C}=\mathrm{AlCl}_{3}+$ Nicotine, $\mathrm{D}=$ $\mathrm{AlCl}_{3}+$ Ascorbic acid, $\mathrm{E}=\mathrm{AlCl}_{3}+$ Nicotine + Ascorbic acid).

\subsection{DISCUSSION}

The widespread use of products made from or containing aluminium ensures its presence in our bodies [20]. There is prolonged retention of a fraction of aluminium that enters the brain, suggesting its potential for accumulation with repeated exposures [21]. The present study was designed to evaluate possible synergetic therapeutic effects of nicotine and ascorbic acid complex against $\mathrm{AlCl}_{3}-$ induced neurotoxicity and oxidative-driven damage in adult male rats.

Data from this present study show that $\mathrm{AlCl} 3$ treatment induced increased production of reactive oxygen species in the prefrontal cortex, evident by an increase in lipid peroxidation and a depletion in the levels of catalase and glutathione peroxidase. This current finding is consistent with the report of Kumar et al., [22]. Fulgenzi et al., [23] implicated mitochondria dysfunction as the possible mechanism fingered in aluminium neurotoxicity. Mitochondria, a major site of reactive oxygen species production, is considered to be a target of oxidative stress. It seems that the oxidative damage to mitochondrial proteins and impairment of mitochondrial bioenergetics may underlie the pathogenesis of aluminium induced neurodegeneration [24].

We reported that the complex of nicotine and ascorbic acid efficiently modulated lipid peroxidation and boosted the antioxidant profile of the prefrontal cortex. The synergetic treatment of ascorbic acid and nicotine also produced better outcomes than nicotine or ascorbic acid only. The neuroprotective effects of nicotine and ascorbic acid have been associated with their antioxidant properties. Ascorbic acid has been demonstrated to be an effective antioxidant. It can act directly by reaction with aqueous peroxyl radicals and indirectly by restoring the antioxidant properties of fat-soluble vitamin E [25]. As evident in this study, the overall consequence of these antioxidant activities is the beneficial control of lipid peroxidation of cellular membranes, including those surrounding and within intracellular organelles. Intracellular free radical attack on non-lipid nuclear material may also be diminished [26]. The antioxidant properties of nicotine may be intracellular through the activation of the nicotinic receptors or extracellular by acting as a radical scavenger in that it binds to iron [15].

Aluminium-induced prefrontal cortex histopathology observed in this study can be attributed to the roles aluminium plays in exacerbating neural levels of reactive oxygen species which culminate in oxidative stress and neuroin- 
flammation [21, 27]. Aluminium has been reported to induce excess iron uptake in neurons [28], resulting in distortion of the intracellular labile iron pool [29]. It then drives a cascade of chemical events that accelerate ROS production beyond what endogenous antioxidant enzymes can cope with [30]. This may lead to the accumulation of intracellular neurofibrillary tangles and extracellular formation of senile plaques composed of the amyloid-beta peptide $(A \beta)$ in aggregated form along with metal ions such as copper, iron or zinc.

The congophilic plaque-like deposition in the prefrontal cortex was still present in the group post-treated with ascorbic acid but diminished in animals post-treated with nicotine and ascorbic acid complex, suggesting the role of nicotine in decomposing amyloid plaque. Nicotine has been shown to resolve amyloidosis in experimental models of $\mathrm{AD}$ [31-32]. On the other hand, evidence suggests that nicotine binds and inhibits the fibrillation of both $\alpha$ synuclein, thus preventing its toxic effects. The presynaptic protein $\alpha$-synuclein is broadly expressed in the brain, and its aggregation is a pathological hallmark of several neurodegenerative diseases [33]. Ascorbic acid potentiates its neuroprotection, primarily by acting as an antioxidant in its capacity enabling it to scavenge for reactive oxygen species, reducing lipid peroxidation, and ultimately sustaining the cellular integrity of the PFC [34].

This study has investigated the therapeutic benefits of the combined treatment of nicotine and ascorbic acid as a treatment regimen in aluminium-induced toxicity by analyzing redox changes and histopathological changes in the prefrontal cortex of Wistar rats. Based on the findings from this study, combining ascorbic acid and nicotine as a treatment regimen has more advantage in the sense that, while nicotine reduced aluminium-induced congophilicity, ascorbic acid significantly boosted the antioxidant profile of the prefrontal cortex..

\section{Conflict of interest}

The Authors declare that there is no conflict of interest

\section{Authors' Contribution}

TAA conceived and designed the study, contributed to analysis of data, manuscript writing and critical revision of the manuscript for intellectual content and final approval of manuscript. OST contributed to study design, data analysis tools, data analysis and manuscript writing. TDO performed data collection, contributed to data analysis tools and analysis of data. OAA contributed to data analysis tools and analysis of data. BSA contributed to data analysis tools, analysis of data and manuscript writing.

\section{References}

1. Halliwell B. Biochemistry of oxidative stress. Biochemical society transactions. 2007; 35(5):1147-50.

2. Cenini G, Lloret A, Cascella R. Oxidative stress in neurodegenerative diseases: from a mitochondrial point of view. Oxidative Medicine and Cellular Longevity. 2019; 2019.

3. Wakabayashi K, Tanji K, Mori F, Takahashi H. The Lewy body in Parkinson's disease: Molecules implicated in the formation and degradation of $\alpha$-synuclein aggregates. Neuropathology. 2007; 27(5):494-506.

4. Nunomura A, Moreira PI, Lee HG, Zhu X, Castellani RJ, Smith MA, Perry G. Neuronal death and survival under oxidative stress in Alzheimer and Parkinson diseases. CNS \& Neurological Disorders-Drug Targets (Formerly Current Drug Targets-CNS \& Neurological Disorders). 2007; 6(6):411-23.

5. Bisht S, Dada R. Oxidative stress: Major executioner in disease pathology, role in sperm DNA damage and preventive strategies. Front Biosci (Schol Ed). 2017; 9:42047.

6. Kaidery NA, Ahuja M, Thomas B. Crosstalk between Nrf2 signaling and mitochondrial function in Parkinson's disease. Molecular and Cellular Neuroscience. 2019;101:103413.

7. Sas K, Robotka H, Toldi J, Vécsei L. Mitochondria, metabolic disturbances, oxidative stress and the kynurenine system, with focus on neurodegenerative disorders. Journal of the neurological sciences. 2007; 257(1-2):221-39.

8. Bragoszewski P, Turek M, Chacinska A. Control of mitochondrial biogenesis and function by the ubiquitinproteasome system. Open biology. 2017; 7(4):170007.

9. Cai J, Yang J, Jones D. Mitochondrial control of apoptosis: the role of cytochrome c. Biochimica et Biophysica Acta (BBA)-Bioenergetics. 1998; 1366(1-2):139-49.

10. R Walton J. Evidence that ingested aluminum additives contained in processed foods and alum-treated drinking water are a major risk factor for Alzheimer's disease. Current Inorganic Chemistry (Discontinued). 2012;2(1):19-39

11. Kawahara M, Kato-Negishi M. Link between aluminum and the pathogenesis of Alzheimer's disease: the integration of the aluminum and amyloid cascade hypotheses. International journal of Alzheimer's disease. 2011;2011.

12. Catassi A, Servent D, Paleari L, Cesario A, Russo P. Multiple roles of nicotine on cell proliferation and inhibition of apoptosis: implications on lung carcinogenesis. Mutation Research/Reviews in Mutation Research. 2008;659 (3):221-31. 
13. Newman MB, Arendash GW, Shytle RD, Bickford PC, Tighe T, Sanberg PR. Nicotine's oxidative and antioxidant properties in CNS. Life Sciences. 2002; 71(24):2807-20.

14. Newhouse PA, Potter A, Levin ED. Nicotinic system involvement in Alzheimer's and Parkinson's diseases. Implications for therapeutics. Drugs Aging 1997;11(3):20628.

15. Hritcu L, Maniu C, Stratulat S. The effects of nicotine treatment on the antioxidant enzimes activity in the rat brain. Journal of Experimental and Molecular Biology. 2007;8(2):212-233

16. Padayatty SJ, Katz A, Wang Y, Eck P, Kwon O, Lee JH, Chen S, Corpe C, Dutta A, Dutta SK, Levine M. Vitamin $\mathrm{C}$ as an antioxidant: evaluation of its role in disease prevention. Journal of the American college of Nutrition. 2003;22 (1):18-35.

17. Chan AC. Partners in defense, vitamin E and vitamin C. Canadian journal of physiology and pharmacology. 1993; 1:71(9):725-31.

18. Spencer LT and Bancroft JD; In Suvarna, K.S., Layton, C. and Bancroft, J.D. eds. Bancroft's theory and practice of histological techniques E-Book. Elsevier Health Sciences. 2018: 104-123

19. Puchtler, H., Sweat, F., Levine, M. On the binding of Congo red by amyloid. Journal of Histochemistry and Cytochemistry 1962:10, 355.

20. Exley C. Aluminium and medicine. Molecular and supramolecular bioinorganic chemistry: applications in medical sciences. 2009:45-68.

21. Tomljenovic L. Aluminum and Alzheimer's disease: after a century of controversy, is there a plausible link?. Journal of Alzheimer's Disease. 2011;23(4):567-98.

22. Kumar K, Dasgupta CN, Das D. Cell growth kinetics of Chlorella sorokiniana and nutritional values of its biomass. Bioresource technology. 2014;167:358-66.

23. Fulgenzi A, Vietti D, Ferrero ME. Aluminium involvement in neurotoxicity. BioMed research international. 2014;2014-2022.

24. Gulcin İ. Antioxidants and antioxidant methods: An updated overview. Archives of toxicology. 2020;94(3):651715 .
25. Olaniyan OT, Femi A, Iliya G, Ayobami D, Godam E, Olugbenga E, Bamidele O, Mali PC. Vitamin C suppresses ovarian pathophysiology in experimental polycystic ovarian syndrome. Pathophysiology. 2019;26(3-4):33141.

26. Rizvi SH, Parveen A, Verma AK, Ahmad I, Arshad M, Mahdi AA. Aluminium induced endoplasmic reticulum stress mediated cell death in SH-SY5Y neuroblastoma cell line is independent of p53. PLoS One. 2014;9(5):e98409.

27. Yokel RA. Blood-brain barrier flux of aluminum, manganese, iron and other metals suspected to contribute to metal-induced neurodegeneration. Journal of Alzheimer's Disease. 2006;10(2-3):223-53.

28. Zatta P, Lucchini R, van Rensburg SJ, Taylor A. The role of metals in neurodegenerative processes: aluminum, manganese, and zinc. Brain research bulletin. 2003;62 (1):15-28.

29. Schleicher E, Friess U. Oxidative stress, AGE, and atherosclerosis. Kidney International. 2007;72:S17-26.

30. Buckingham SD, Jones AK, Brown LA, Sattelle DB. Nicotinic acetylcholine receptor signalling: roles in Alzheimer's disease and amyloid neuroprotection. Pharmacological reviews. 2009; 61(1):39-61.

31. Hernandez CM, Kayed R, Zheng H, Sweatt JD, Dineley KT. Loss of $\alpha 7$ nicotinic receptors enhances $\beta$-amyloid oligomer accumulation, exacerbating early-stage cognitive decline and septohippocampal pathology in a mouse model of Alzheimer's disease. Journal of Neuroscience. 2010; 30(7):2442-53.

32. EI-Agnaf OM, Irvine GB. Aggregation and neurotoxicity of $\alpha$-synuclein and related peptides. Biochemical Society Transactions. 2002; 30(4):559-65.

33. Olajide OJ, Yawson EO, Gbadamosi IT, Arogundade TT, Lambe E, Obasi K, Lawal IT, Ibrahim A, Ogunrinola KY. Ascorbic acid ameliorates behavioural deficits and neuropathological alterations in rat model of Alzheimer's disease. Environmental toxicology and pharmacology. 2017; 50:200-11.

34. Abayomi TA, Tokunbo OS, Atere TG, Adeleke SO. Role of Vitamin $\mathrm{C}$ and $\mathrm{E}$ in sodium azide induced oxidative stress in prefrontal cortex. Journal of Anatomical Sciences. 2018; 9(1) 88-94. 